\title{
Graduate Students' Evolving Perceptions of Writing Collaboratively
}

\author{
Anita H. Ens \\ Karen Boyd \\ University of Manitoba \\ L. Allyson Matczuk \\ Warren T. Nickerson \\ Manitoba Education
}

\begin{abstract}
As members of a language and literacy doctoral cohort, we four authors attempt to situate ourselves within a community of practice in which knowledge is socially constructed. In this context, we explore our identities as collaborative writers and researchers. This paper documents the self-study that we undertook while collaboratively writing scholarly articles. We framed our research with three questions addressing process, product, and theory. How do individual writers approach a collaborative assignment, both emotionally and cognitively? Do writers perceive a difference in the quality of collaborative text versus individual text? How does experience connect to theory? Our experience indicated an increased consciousness of our writing processes and made us more aware of issues of style, audience, and clarity. Furthermore, the data emphasized the relational aspect of collaborative writing. We concluded that collaborative writing has a place in doctoral studies for its potential in increasing dialogue within a discourse community.
\end{abstract}

\section{RÉSUMÉ}

Nous sommes une cohorte doctorale de quatre étudiants dans le domaine de la langue et de la littératie. Nous formons une communauté de praticiens au sein de laquelle le savoir est construit socialement. Dans ce contexte, nous explorons nos identités respectives en tant que collaborateurs en recherche et en écriture. Cet article documente l'étude 
que nous avons entreprise en rédigeant collaborativement des articles académiques. Notre projet était encadré par trois questions portant sur le processus, le produit et la théorie : Comment un auteur aborde-t-il une tâche collaborative aux niveaux émotif et cognitif? Les auteurs perçoiventils un écart entre la qualité d'un texte rédigé en collaboration et celle d'un texte écrit individuellement? Quels rapports y a-t-il entre l'expérience et la théorie? Notre expérience a révélé une prise de conscience accrue quant au processus d'écriture de chacun et aux problèmes de style, de lectorat et de clarté. En outre, l'aspect relationnel de l'écriture avec collaborateurs s'est vu amplifié. Nous concluons que l'écriture collaborative a sa place au niveau doctoral en raison de son potentiel d'amélioration du dialogue au sein d'une communauté discursive.

Discussion regarding the purposes and intents of doctoral programs continue to centre on complex and multifaceted questions (Harris, Freeman, \& Aerni, 2009). In education, doctoral students are being prepared for a wide range of opportunities. What remains central in these programs is preparation to assume a place in the research community. The academic research community itself is in a state of flux, as issues regarding collaborative scholarship raise questions in relation to tenure, promotion, and publication (Facione, 2006). As members of a language and literacy doctoral cohort at a western Canadian university, we watch the evolving nature of scholarship with interest as we attempt to situate ourselves within the community of practice. In the process it has been necessary to explore our own identity as collaborative writers and researchers.

Throughout our initial coursework, our readings informed us of the social dynamic of writing (Clark, 1990; LeFevre, 1987; Wells, 1999). What we read, talked about, and listened to was reflected in our writing. The social collectivity of thought allowed us to move our ideas forward with a common framework. We were "inventing by interaction" (LeFevre, p. 68). Through this invention, individual pieces of writing were produced. Each piece of our solely authored weekly writings for the single audience, our professor, was nonetheless multivoiced. The understanding of the impact of others on our writing encouraged us to investigate the collaborative scholarship that takes place with multiauthored writing. This paper documents the self-study that we undertook while collaboratively writing scholarly articles.

\section{BACKGROUND}

Over the past twenty years, much educational research on collaborative writing (CW) has been conducted. Starting with the work of Bruffee (1984), Gere (1987), LeFevre (1987), and Ede and Lunsford (1990) (also identified by Durst, 2006), collaborative writing research and practice has resulted in an established body of literature marked by a learning framework in which knowledge is socially constructed. Both Vygotsky's and Bakhtin's theories inform the social construction of 
knowledge. Vygotsky suggested that signs and symbolic systems such as language only gain meaning as they are used in relation to other people and within society (Daniels, 2005; Vygotsky, 1962). Moreover, social interaction can affect an individual's quality of learning. When a more expert other, such as a teacher or peer, works with a learner by providing supports in a way that enables the learner to accomplish tasks the learner would not be able to complete alone, the learner and the more expert other are working in what Vygotsky called the zone of proximal development (Hedegaard, 1996; Vygotsky, 1978; Wells, 1999). Wood, Bruner, \& Ross (1976) used the term scaffolding to include a range of supportive behaviours by a knowledgeable other that lead a learner to greater understanding and independent task performance. Recent studies report this type of scaffolding happens in CW (AlJamhoor, 2005; Benton, 1999; Nixon, 2007). Other studies have shown that writing with others allows participants to coconstruct knowledge through negotiation of roles and meaning (Chiang, 2002; Porras-Hernandez, 2001).

Bakhtin's contributions to social constructivist thought regarding dialogue (Bakhtin, 1981,1984/1994; Farmer, 1998; Halasek, 1999) provide a helpful paradigm when considering the benefits of $\mathrm{CW}$. For Bakhtin, language is multivoiced and imbued with nuance and history. Words carry political, historical, and cultural meanings that have particular significance at the time of utterance, as well as future meaning as that text enters new dialogue with subsequent voices. Capitalizing on the dialogic nature of language, engagement with others in the process of writing creates intentional opportunities for developing relationships and generating knowledge.

Given the social nature of writing and the relational intricacies involved in writing collaboratively, it should not be surprising that both affect and cognition influence $\mathrm{CW}$ processes. Exploring the interrelation of thought and word, $\mathrm{Vy}-$ gotsky (1962) wrote

We have in mind the relation between intellect and affect. Their separation as subjects of study is a major weakness of traditional psychology since it makes the thought process appear as an autonomous flow of "thoughts thinking themselves," segregated from the fullness of life, from the personal needs and interests, the inclinations and impulses, of the thinker. (p. 8)

Linking individual motivations and feelings to intellect offers research a way to consider the personal within the social context. Recent studies indicate that these relationships are being noticed in studies of CW.

A review of research studies conducted in the last ten years and available through ERIC, Academic Search Complete, Proquest Dissertations \& Theses, and Theses Canada Portal offers a sense of the current understandings of CW. For this study, background information on process and product was used from two abstract reviews, one focusing on the $\mathrm{CW}$ of children and the other on $\mathrm{CW}$ in the past ten years. In the latter, studies were limited to those with $\mathrm{CW}$ in the title in the ERIC search. We engaged in further reading to explore more deeply definitions 
of CW, practical examples of its implementation, and the experiences of study participants who were university students, faculty, or professionals (Al-Jamhoor, 2005; Benton, 1999; Chiang, 2002; De Silva, 2007; Gousseva-Goodwin, 2000; Kim \& Eklundh, 2001; Maher et al., 2008; Mitchell, 2003; Nixon, 2007; Porras-Hernandez, 2001; Ritchie \& Rigano, 2007; Sakellariadis et al., 2008; Straw, Atkinson, Baardman, \& Sadowy, 1996; Sutton, 2002).

The reviewed research offers some insights to cognitive and emotional aspects of collaborative writing. For example, CW improves motivation and attitude toward writing tasks (Benton, 1999; Standley, 2006, Vendramin, 2006). In addition, academic and social identities are developed through CW (Klass-Soffian, 2004; Maher et al., 2008; Straw et al., 1996; Vendramin, 2006; Wilson, 2008). Relationships tended to be emphasized in the reporting. For instance, among younger writers, Standley found that students bonded while working together for five weeks with one activity being CW. Ritchie and Rigano (2007) noted the "highly charged emotional and intellectual experience" of academics writing side-by-side as creating a synergistic dynamic unique to collaborative relationships. The process is not without pain: personal, cultural, or content-related conflict can arise (Al-Jamhoor, 2005; Benton, 1999; Chiang, 2007; Sakellariadis et al., 2008). However, Nixon (2007) and the same authors who reported conflict found that collaborative writers develop a better understanding of the craft of writing, knowledge construction, and culture from multiple perspectives.

Researchers noted the complexity of CW relationships (Benton, 1999; KlassSoffian, 2004; Sakellariadis et al., 2008; Sutton, 2002). Klass-Soffian found that "strong leadership, defining roles and/or role flexibility, an atmosphere of trust, a spirit of cooperation, commonality of purpose, student accountability, and establishing solid group identity" (abstract) were required for successful group collaboration. Ritchie and Rigano (2007) also talked about the intricacies of negotiating roles and process and the comfort that developed between them through their ongoing interaction. For Maher et al. (2008), social and emotional support were integral to their writing. Benton suggested that mutual accountability might encourage stronger involvement with the work.

Sakellariadis et al. (2008) documented the process of a large group of faculty and student collaborative writers exploring identity construction. Their report illustrated the complexities involved in negotiating uses of technology, the role of face-to-face meetings, and the challenges to communication. Both process and relationship were integral to the evolving work, and the paper is littered with emotion-laden reflections. For example, to start each passage about sharing writing online, all three voices reference feelings, using words such as "scary," "exposed and quite alone," and "disappointing." All three writers spoke of the need for response from their collaborators. In Kim and Eklundh's (2001) study, participants' revisions of their collaborators' work was guided in part by not wanting to hurt others' feelings. Likewise, Maher et al. (2008) describe group members' initial reluctance in commenting on each others' work. 
Most of the studies that examined quality of written product considered young writers. There is evidence that quality of writing is improved through collaborative writing although it is not necessarily the collaboratively written products that showed improved quality (Benton, 1999; Sutherland \& Topping, 1999; Yarrow \& Topping, 2001). In Sutherland and Topping's study, three groups of eight-year-olds engaged in writing. Their study found improvements for various ability pairings using individual and CW writing tasks. Topping, Nixon, Sutherland, and Yarrow (2000) found gains in the individually written pieces by five-year-olds comparing their writing before and after paired writing with their 11-year-old tutors. Similarly, Vendramin (2006) found that after writing online collaboratively, elementary students' text showed improved writing conventions. Furthermore, strong writers improved from working with stronger, older writers. Collaborative writing was shown to improve organization and vocabulary elementary school students' writing in Standley's (2006) study, but this was not compared to individual writing. However, not all CW is of high quality (DeSilva, 2007; Topping et al., 2000). DeSilva suggests that explicit instruction on process can assist in producing quality writing.

Based on the reviewed studies, more research on graduate students writing collaboratively as well as studies linking $\mathrm{CW}$ with quality of writing for older writers is needed. Therefore, this examination of our collaborative process and product adds to collective understandings of $\mathrm{CW}$ processes and products and offers insight into the question of whether they have a place in the academic culture at the doctoral level.

\section{Definitions}

Definitions of collaborative writing are many and may leave readers with more confusion than clarity (Hill, 2003). In this study, we considered the seminal definitions by Ede and Lunsford (1990) and a few more recent examples and then constructed our own definition. Ede and Lunsford and other scholars whom they cite, such as Reither, conflate writing and collaborative writing. Since all language is socially constructed, all writing is collaborative. However, Ede and Lunsford distinguish between dialogic $\mathrm{CW}$ in which members work together on all aspects of the project and hierarchic $\mathrm{CW}$ in which members assign each other or themselves different parts of the project. Any project may include both types of CW. More recently, Ritchie and Rigano (2007), within their description of CW, defined cooperative and lead writing. In cooperative writing, contributors take turns, negotiating different sections to write before (usually) the first listed author merges the different sections and voices. In lead writing, one person takes responsibility for writing the first draft; the lead would be rotated for subsequent papers. Although lead writing was a common practice among the people that Ritchie and Rigano interviewed, their own CW process involved writing side-by-side in regular sessions for which each came prepared. This type of writing involves negotiating control, for example of the keyboard; reflexivity; and emotional investment. 
For the purposes of this paper, it was necessary for us to come to a common definition of what we meant by collaborative writing. We could not assume that although we had participated in the same experience that our definition would be shared. In order to create a common definition, each of us wrote a definition and emailed it to Anita. This process allowed us to ensure that each voice was heard equally rather than attempting to create a definition together. Anita attempted to compile the responses into one definition and then sent the synthesized definition back to the other members for review and revision. The four individual definitions were as follows:

1. The crazy insight I had into the collaborative writing experience was that all our writing is collaborative. We negotiate topics, explore ideas, challenge support, and point out omissions. The trouble is, this negotiation often doesn't happen until much later in the process. Collaborative writing invites others in earlier, acknowledges the impact others have on the writing process, and credits others for their insights and voice (Warren).

2. Two or more authors composing a single piece of writing by either discussing or contributing content, structure, style or form (Allyson).

3. Collaborative writing is a process that encourages two or more people to have ownership over the produced text (Karen).

4. Collaborative writing involves more than one person committed and contributing to a text piece but does not assume co-authorship (Anita).

What was common in these four definitions was the idea that $\mathrm{CW}$ does not just mean the production of text. The "impact others have on the writing process" includes discussion, support, insight, editing, or revision as well as the actual sharing of the keyboard. These ideas also reflect some continuing issues that we were working out regarding ownership and authorship of text. If "all our writing is collaborative," then how do we accurately and validly give credit and acknowledge impact? These discussions continued as our four pieces moved closer to completion. It became apparent that the lead author was usually more open to crediting coauthors than were those who may have had less direct writing involvement and may have contributed primarily in discussion. As some articles are still in progress, the discussion is ongoing. Issues of authorship as well as the question of what amount or kind of contribution constitutes collaborative writing, not simply collaboration, is reflected in the fourth definition, "does not assume coauthorship." Through this process, we have discovered that assumptions cannot be made, but conversation must be open and transparent to make thoughtful decisions and reach consensus.

We accepted the final collaborative definition, as put together by Anita, without revision. At this point, we had established a sense of trust in the quality of each other's writing. The discussion and the act of creating individual definitions seemed to make each of us comfortable with the representation of our ideas in this final definition:

Collaborative writing is a process that involves two or more people committed to a jointly composed text. Negotiation begins early in the process 
and includes exploring topics; challenging; supporting; and pointing out omission; while addressing content, structure, style or form. Collaborators do not assume coauthorship but acknowledge the impact, insights, and voice of others.

\section{Research questions}

To frame our own research, we began with three research questions that dealt with process, product, and theory. How do individual writers approach a collaborative assignment, both emotionally and cognitively? Do writers perceive a difference in the quality of collaborative text versus individual text? How does the experience of the writers connect to the theory underlying collaborative writing? The first two questions guided our reflections and served as a framework for setting questions in order to collect data and analyze results. The third question served to ground our experience in the literature.

\section{METHODOLOGY}

As education doctoral students we have become more aware of the integral nature of self-study as a part of teaching and reflective practice. Pithouse, Mitchell, and Weber (2009) write that there has been increased research into the "processes, emotions, complexities, nuances, values, cultural templates, embodiment, and the political and social contexts of teaching" (p. 44). This research contributes to the idea of the holistic nature of our learning process in an academic community. Our research study attempts to legitimize our use of self-study in a collaborative community. Hamilton and Pinnegar (1998) define self-study as the "study of one's self, one's actions, one's ideas, as well as the 'not self'" (p. 236). LaBoskey (2004, as cited in Pithouse, Mitchell, \& Weber, 2009, p. 45) identifies four aspects central to self-study: Self-study (1) is improvement driven; (2) involves interactions with colleagues, students, literature, and our previous work; (3) employs multiple, primarily qualitative methods; and (4) is undertaken with an intention to go public.

\section{Participants}

The participants in this study were the four authors of this article. All four were members of a language and literacy doctoral cohort at a western Canadian university. We were in the first year of the cohort and took two required courses together. Anita, Warren, and Allyson had known each other prior to the start of this program through their master's program while Karen was new to the others. All had completed individually authored master's theses in the discipline of Language and Literacy; two were qualitative and two were quantitative studies. The CW exercise was an assigned task in the core courses; however, choice of collaborators and task was left to the participants. The assigned task was to complete four coauthored articles, each based on one of the studies in the four theses. 


\section{Method}

The collaborative writing group was established in the fall of 2008 and some negotiation occurred as coursework was being completed, but the bulk of the work took place in second semester. At the first CW meeting in January 2009, we decided to divide the roles so that each of us was lead author on an article arising from our original study. We then formed two pairs according to convenience based on shared workplace and type of original study, qualitative for one pair (Anita and Karen) and quantitative for the other (Allyson and Warren). Each pair would work together on two papers with the other pair providing more direct input at the editing stage but with the option of revising text at any point. At this first meeting, Anita and Karen devised a timeline which included work on the two lead papers as well as preparation for the reporting of the self-study at a graduate student symposium. Allyson and Warren, though not able to copresent at the symposium, agreed to be coauthors and to participate in other ways. The timeline was quite broad including tasks such as "choose journals, conduct initial abstract search, and share drafts" but proved to be useful in keeping the writers on track.

Data were collected from October 2008 to April 2009. Sources included biweekly meeting minutes, exit slips, individual journal responses, emails, participant interviews, and reflections on the final products. Data formally collected during meetings included meeting minutes that were either taken in note form or audio taped as well as exit slips, which were ten minute individual writings immediately following meetings that synthesized information and provided opportunity for immediate reflection on the process. Participant journal responses and emails were collected as they occurred but were not formally assigned. Final participant interviews and reflections of products were collected at the end of April 2009.

\section{DATA ANALYSIS}

Data were analyzed using the initial research questions as a frame. Anita and Karen divided up the data sources and charted and coded the data based on the questions. Each data source was considered in three initial categories, Process: Cognitive; Process: Emotional; and Product. After an initial coding of the data we met and through discussion added a fourth category, Process: Logistics. Although we were investigating the social nature of writing, our implicit and mutual default to categorize data items was towards a cognitive model for writing process, acknowledging the emotional impacts of writing together and of product as separate parts of the process.

\section{Process: Cognitive}

The cognitive model of writing proposed by Flower and Hayes (1981) accounts for individual differences in the composing processes of writers. They suggested that a series of cognitive processes were employed by writers recursively. 
These processes become more sophisticated with the growing experience and consciousness of individuals' approaches to composition. As we analyzed the data, any comments that dealt with the actual generation of text or the consciousness of a participant regarding the composition process were entered as Process: Cognitive. Throughout the data, we articulated consciousness of our own writing process. Ideas of structure, audience, and style were mentioned in exit slips, meeting minutes, and final responses. Interestingly, the actual writing process was seldom mentioned in email correspondence.

Collaboration seemed key to the increasing consciousness of certain processes. Allyson found that the conversations with collaborators were valuable in "forcing me to refine and clarify" the writing. For Karen, the "ongoing feedback challenged my perceptions of the writing." Having feedback from other thinkers invested in the outcome offered opportunities to think differently about the purpose of the writing task in a way that having only the feedback of an instructor might not have prompted. Collaborators imposed a process of constant revision, intensifying the recursive nature of the generating, translating, and revising. Warren found that "live critical voices are powerful but emotionally challenging," but he "carried the critical voices into the drafting process." He developed confidence in articulated ideas through defending them in conversation with the collaborators.

Collaboration also generated thinking in a way that was different than writing alone which in turn affected subsequent writing. In this CW process we held multiple simultaneous roles. Even when we were not the person whose writing or ideas were being addressed by the others, or as we referred to it as "being in the hot seat," we were given the opportunity to witness how others think, both through reading and through listening. By engaging in our collaborators' processes, we learned about our own thinking and processes. As Karen commented, "I had the opportunity to see other people's writing in process; I didn't realize how seldom I get to do this." At an early stage in our collaboration, the articulation of our writing process seemed necessary as a defence mechanism. During a particularly heated sharing session, questions regarding process and content had the tendency to be taken as criticisms. It was not until later that we opened up regarding our process. Anita wrote, "Talking about the writing is also a key point to this process." It was important for us to move away from focusing solely on the content to including the process that led us to the content.

In addition to the cognitive process of writing, this collaborative work gave us the opportunity to cognitively process our content learning. As Warren noted:

Collaborative writing created a space in which each could appreciate the ways in which each researcher's work contributed to a new understanding of language and literacy. The collaboration was fertile ground for coming to new insights into the nature of the dialogic learning of our subject, but also the dialogic learning of doctoral students in a language and literacy cohort. 
Through our conversation and writing, we explored ideas relating to feedback; the value of talk, reading and identity; one-to-one tutoring; and the many opportunities for scaffolding. Hearing and reading each others' perspectives on the issues we had explored in our theses became a valuable way of building knowledge.

\section{Process: Emotional}

Much of the research on collaborative writing stressed the quality of the relationship as influencing the success of the writing (Al-Jamhoor, 2005; Benton, 1999; Chiang, 2002; Maher et al., 2008; Nixon, 2007; Sakellariadis et al., 2008; Straw et al., 1996). As this project was the first major collaboration effort for most of us, a large part of the data documented the developing relationships and the emotional complexity required. While analyzing the data it was noted that at times the emotional comments were connected to the writing task, while other data related to emerging relationships that served other purposes but may have contributed to the success of the collaboration.

At the beginning of the project we were slow to start and emotions were often mentioned in the reflections. Confidence in the collaborative process and in each other needed to be developed. Throughout the data, emotion-laden words such as "shy," "tentative," "hesitant," "awkward," "uncomfortable," "insecure," and "uncertain" spoke to the complexity of a new relationship. However, optimism was also present. As Allyson commented, "being accountable to the group will be motivating and reassuring." There was a pull within the individuals and as a group between the possibilities of and fear of the unknown.

Time spent with the group was felt to be valuable despite the ongoing tension between insecurity and productivity. A month before expected completion, we felt the impact of time pressures, while at the same time valuing the time we were taking to meet and talk. As Allyson put it, "This [meeting] was good. Time to interact with primary and secondary partners was valuable. I didn't feel like I've moved as far forward as I would've liked, but I'm on the cusp." Appreciation for time spent with the group was mentioned by another, who noted not only accountability as motivating, but cited talk as creating ownership of each others' lead papers and creating a learning journey within the doctoral program.

Regardless of the value in time spent together, the $\mathrm{CW}$ process required an investment in time that in some ways became an emotional stress. Karen commented, "it was good to carve out this time to work, but, like carving, it seems to be somewhat bloodletting." These dichotomies of emotions seemed to follow a recursive pattern similar to the cognitive one. At times, we were positive and hopeful, using words like "optimistic" and "excited" and at other times frustrated and worried, and writing about being "vulnerable" and "misunderstood."

Communication beyond the writing project indicated the trust that had developed between the participants. This was most evident in the email correspondence. Between October 6, 2008 and April 27, 2009, over 211 email messages were 
documented. As noted previously, very few of these messages addressed the actual writing. Topics of the emails included sick kids, terrible roads, busy schedules, vacations, hockey, and life. One particular snowy Sunday involved a series of emails in which participants shared their exhaustion and concerns with adding a doctoral program into their lives. We also took the opportunity in emails to value these growing relationships. Following a presentation on the collaborative process, Anita wrote,

We were grateful to have been able to offer specific examples from your voices. Doing the presentation gave me further realization of how I am growing to really value our foursome. I really do hear all your voices in my head and that's a good thing.

And despite the challenges of the program, Karen wrote,

At the risk of sounding sappy, could I just say how much I am appreciating this learning community. This was brought home to me when I watched other students present and was reminded about how isolated I felt during my master's program. I like that this learning seems much more public, not just between me and the professor, much more authentic.

The "hot seat" incident, the presentation, and the "email" weekend are examples of critical junctures that gave us context to measure our growth and change in this process. These events themselves did not cause the change in the individual writers, but they were shared experiences that contributed to our learning community. Exit slips and emails document additional critical incidents that occurred at different times and for different reasons for each of us.

The time that we invested in this initial CW process brought us to the point in our relationship where we now see other collaborations not only as possible but also, for some of us, as preferred. Allyson who would rather "pick moss from between the patio stones" than write noted, "I would [now] rather write together than alone." All four of us indicated that collaborating on this course assignment laid the groundwork for future writing together.

\section{Process: Logistical}

Logistics was a category that had not been identified in the initial questions but emerged from the data. The exit slips noted that setting agendas and timelines helped us to focus and manage the tasks. Email correspondence became a primary way to deal with logistics. Thirty-nine emails dealt specifically with arranging meetings. While a solitary writer controls all parts of his or her own process, collaboration requires communication on how, when, and where writing will take place. This communication involves a commitment of time and negotiation to set the stage for an effective writing experience. 
Initially, decisions on how to proceed were tentative. With little previous experience, the group was unclear on what decisions needed to be made. It was noted, "It wasn't until the expert provided feedback that the novices felt able to proceed." In our case, the expert was the professor who had assigned the CW task and who had personal experience of writing collaboratively. His expert feedback catalyzed a critical incident changing the dynamics of the CW experience. The four of us had been cautious in providing feedback, worrying about our collaborators' feelings. Our professor was much more willing and able to engage us in critical response to the writing. This process was initially distressing as each of us felt put in the "hot seat" but this modeling by our professor moved us to another level of trust and professional dialogue.

The other logistical piece that the group struggled with was the actual assigned task. The course required us to write a publishable article based on the data in each of our master's theses. Initially, we saw this as an efficient way to proceed given that the research had already been completed. As the project progressed, the task became a logistical issue. Allyson reflected,

The negotiations of roles in the collaborative team were tentative and seemed to take a long time. We were all personally invested in our theses; it was a bit like offering up our youngest child for a group to evaluate and shape up. While the owner of the research may have felt uncertain about putting our best effort out there, the other members of the collaborative felt uncertain about making suggestions. I guess the "do unto others" ethic is too deeply ingrained in us all. We're a polite group.

A combination of factors was at play. We were expert in our own topic areas yet hesitant to offer feedback in the others' areas. Moreover, we were not quite sure how an individually conducted study could evolve into a collaboratively written article. We were not sure how each of us might come to feel ownership of the topics, partly out of respect for the investment each of us had in the original studies. Negotiating these details logistically required time, trust, and tact. This negotiation was done over time and repeatedly as we gained confidence and trust in our relationships. When Allyson's article was ready for submission, Karen broached the topic of removing herself as a coauthor as she felt that her contribution to the final product was minimal. Allyson said that she felt comfortable leaving the name on as our definition of collaboration went beyond the actual production of text.

\section{Product}

Our goal was to produce four coauthored articles by the end of the study. Four articles were completed; however, we are continuing to work on revision and editing because we are "not completely satisfied with the final product." As the deadline loomed to hand papers in for grading, writers worked more individually, with collaboration confined to the imagination. This caused Karen to wonder whether the writing was in fact collaborative. In addition, because the coauthored 
articles were assigned, lurking questions surfaced throughout the process as to what we were measuring, particularly in relation to the purpose of both the writing and the process. Perhaps part of the assignment was to create better papers through collaboration. On the other hand, rather than focusing on product, maybe the desired outcomes were less tangible and more process focused. Perhaps the intent was to offer a learning experience of developing a community of thinkers in dialogue together.

Despite our lack of clear criteria for successful product, the final reflections indicated each of us found some satisfaction in the quality of writing that resulted from working together. When asked to describe the final product in a final reflection, Warren felt that the expression of ideas was "more concise because of the feedback." Through conversation, text was significantly rewritten: The ongoing feedback was felt to have improved the clarity and composition of the papers. Anita stated clearly that, "it made my writing better." Nonetheless, product was infrequently addressed in the data, and statements referring to the quality of the products is purely anecdotal rather than comparative.

\section{Connection to theory}

Our third research question examined how our experience connected to theory. Our data supported other research findings related to product, process, and relationship. For example, studies by Vendramin (2006) and Standley (2006) indicated that $\mathrm{CW}$ improved the structural components of pieces. For Maher et al. (2008), developing a meta-language together allowed group members to discuss content, structure, and expression of ideas. Through discussion and peer feedback, writers improved their clarity of thinking and expression. Similarly, our experience involved an increased consciousness of our writing processes and made us more aware of issues of style, audience, and clarity. Our writing pieces were also edited and reviewed more often in the collaborative process, resulting in what we perceive to be more polished final pieces.

As in the reviewed research, our data emphasized the relational aspect of collaborative writing. Time needed to be invested to develop trust, negotiate roles, and structure the process. As a result of working together in this group, we see this time as an investment in future writing endeavours. We have established much of the groundwork to move forward with further collaborations. As Anita wrote,

I feel very comfortable saying blunt, not always diplomatic, and downright opinionated things because I trust the others to have equally outrageous statements and to challenge, amend, soften, or substantiate mine. In short, I think trust is developing and already there as a base.

As already suggested by Straw et al. (1996), CW needs to be undertaken with an understanding of the time investment and the importance of trust. The CW task must also recognize the complexity of the relationships. Both the trepidation 
and the power in building these relationships were evident in our study as in the research reviewed. "Walking on eggshells" (Straw et al., p. 57) and the "sense of belonging" (p. 57) were mirrored in our study by hesitancy, awkwardness, and vulnerability contrasted with valuing others' voices in our heads as part of a learning community.

\section{CONCLUSIONS AND IMPLICATIONS}

Although our collaborative writing continues, some findings of our self-study can be summarized. Not unexpectedly, we experienced recursive patterns in both cognitive and emotional aspects of the writing. In terms of cognitive process, we gained an increased sense of our own writing through exposure to each other's thinking and writing processes, much like the metalanguage referred to by Maher et al. (2007). Moreover, we built knowledge together. Emotional benefits included increased confidence, trust, and affect towards the writing process. Two areas identified as requiring further study came out in the area of logistics and measuring quality of product.

Logistical implications of the time and the related emotional implications regarding trust arose from this study. First, our data suggests that short-term writing partnerships may not best take advantage of the relational aspect of collaborative writing. Second, our particular task contributed to the complexity of relationship building by adding an ownership component to the data that needed to be worked through. Straw et al. (1996) noted the dissociation from text that sometimes accompanies CW. In successfully coauthored texts, "the text must remain open and pliable in order for the blending of voices to happen" (p. 58). Starting with an individually researched thesis added weight to feelings of ownership. A writing task without this complication may create conditions that allow for more efficient development of roles.

The research that focused on writing quality dealt mostly with younger children. Although this study was not designed to measure quality of writing, a research question did solicit our perceptions of writing quality. Our data suggested that we felt that our writing had improved, but we had established no criteria for measuring improvement or framing our perceived differences between individually and collaboratively written texts. Most of the perceived improvements were at the level of ideas which were better developed as a result of the conversations or in terms of clarity of expression. Based on this study, it would also be difficult to assess whether our CW is better than each of our previous individual writings or whether our individual writing has improved as a result of this collaboration. More research is needed into writing quality and CW.

Engagement through dialogue has been cited in the research on CW. For example, Sakellariadis et al. (2008) describe the movement of ideas and text, face-toface and writing apart, in their CW group: "Now our writings are re-creating new conversations on a landscape of paper" (p. 1216). Or as Ritchie and Rigano (2007) 
note, "...we each can recall meaningful intellectual and emotional spaces of being together that in turn help us to reconstruct these spaces metaphorically" (p. 133) as they imagine possible reactions of the other based on their experience of writing side-by-side. Similarly, what we engaged in throughout this process was extensive dialogue. Through discussions about writing, about our topics, about our learning, and about life we added each other's voices to our own. Our thoughts became multivoiced. From a Bakhtinian perspective, this engagement with others, this layering of language, gave us the opportunity to construct new knowledge. For this reason alone-that is to engage in fruitful dialogue-collaborative writing has a place in doctoral studies.

\section{EPILOGUE}

One year has passed since the conclusion of our doctoral course that housed the collaborative writing assignment. At the point of this writing, two of our articles have been submitted to journals for publication. One was accepted with revisions, and it has been successfully resubmitted. The second received mixed reviews but revision and resubmission were suggested. The final two articles continue to be revised and prepared for submission. This paper, also accepted for publication, is the fifth of our collaborative endeavours. Anita, Allyson, and Warren continued to write together, producing a sixth collaborative paper on the relationship among beliefs, practices, and professional development of teachers. Karen chose not to join them, only because of the time commitment required. While collaboration distributes the workload, it also increases the time required. The decision not to participate was made regretfully. Based on this paper and the collaboration on the sixth paper, Anita individually wrote a paper to be presented at a conference spring 2010.

In keeping with the original configuration of writing relationships, the reviewing process of the first article to be accepted for publication involved the lead writer, Allyson, the professor, and paired writer Warren. All of us read the manuscript versions in their iterations, but the timing and type of each of our revisions was different. Allyson and the professor reviewed the statistical analyses after which the lead writer incorporated reviewers' suggested changes. She sent the manuscript to all collaborators. Thereafter, Allyson, Warren, the professor, and Anita met to discuss the changes face-to-face, line-by-line. Anita observed and wrote notes, offering only minimal interjections. This meeting was led by the professor who had made substantial revisions, with also weighty contributions from the paired author who had likewise carefully responded to the whole paper. Allyson discussed each point with the others, noting some points and changing some points in text. After this meeting, Allyson and Warren significantly rewrote the introductory section, and then the other two offered proofreading and minor revisions. One document was worked on in sequence using Word's track changes feature and appending each writers' initials to the document name before sending it back to the group via email. 
The second article that was accepted for publication met with contradictory reviews, with one reviewer recommending significant changes. Anita as lead writer met with the professor to discuss process, as Anita and Karen were entering their 90-day candidacy period, limiting the time they might spend on manuscript revisions. At the point of writing, the professor, one of the collaborating authors, may initiate the revisions until the other writers are able to contribute.

This paper, our fifth effort together, was revised in much the same manner that it was written. Anita made some revisions initially and then sent the revised manuscript to Karen. We met face-to-face to discuss the reviewers' comments, changes already made, and ensuing process. Sitting for two and a half hours side-by-side at the computer, holding hard copies, we itemized tasks, discussed content, and noted both. Again, we only worked on one document, but rather than using track changes, we followed our system of adding new text as well as commentary directly into existing text, using bold font and changing font color if necessary. After the bulk of the changes had been made, we emailed the other two for approval of details, text, and use of names.

As we submit this article for publication we can say that what has continued to develop and have an impact on our evolving academic identity is the trust that we have developed as a group. The $\mathrm{CW}$ process, although initially imposed on us, provided a professional community that has allowed for ongoing discussions about our own work. It has also provided us with personal support intended by the doctoral cohort structure of our program, but it was the CW subgroup that best encouraged the collegiality and friendship that is desirable during a doctoral studies program. The difficulty that we are facing at the moment is writing our candidacy exams. As a highly individual process, the candidacy requirements limit, to the point of exclusion, any input from others, including discussion, into our writing. Our research in language and literacy and our CW process have convinced us that talking and thinking together enriches our individual thinking. As Anita commented,

I find myself thinking like Allyson, Warren, or Karen and wondering if I ever thought differently. It's hard for me to pick apart which pieces I have come up with on my own and which ones are integrated from the conversations we've had.

The social nature of language improves the thinking necessary for quality writing. Having experienced this, the solitary nature of our candidacy exams is not only personally difficult but philosophically less than productive.

Collaborative writing has become part of our practice. Responses to our work through conferences and reviews suggest that our experience is unique in the doctoral studies community. We would suggest that this needs not only further research but also more extensive practice. 


\section{REFERENCES}

Al-Jamhoor, M. M. (2005). Connecting Arabs and Americans online to promote peace and to increase cultural awareness: A descriptive study about Arab EFL learners' perceptions, practices, behaviours and attitudes towards computer-supported collaborative writing strategies and technologies (Doctoral dissertation). [Abstract]. Retrieved from ProQuest Dissertations and Theses database. (AAT 3164696)

Bakhtin, M. M. (1981). Discourse in the novel. (M. Holquist \& C. Emerson, Trans.), In M. Holquist (Ed.), The dialogic imagination: Four essays (pp. 259-422). Austin: University of Texas Press.

Bakhtin, M. M. (1994). Problems of Dostoevsky's poetics, 1963. In P. Morris (Ed.), The Bakhtin reader: Selected writings of Bakhtin, Medvedev, Voloshinov (pp. 103112). London: Edward Arnold (Publishers) Ltd. (Reprinted from Problems of Dostoevsky's poetics, C. Emerson, Trans., 1984, Minneapolis, MN: University of Minnesota Press.)

Benton, R. E. (1999). Cognitive and affective dimensions of academic and professional collaborative writing (Doctoral dissertation). [Abstract]. Retrieved from ProQuest Dissertations and Theses database. (AAT 9947175)

Bruffee, K. (1984). Collaborative learning and the conversation of mankind. College English, 46, 65-82.

Chiang, T. T. (2002). Collaboration-based instruction and second language writing: How teachers impact the quality of student work in collaborative writing classrooms (Doctoral dissertation). [Abstract]. Retrieved from ProQuest Dissertations and Theses database. (AAT 3056174)

Clark, G. (1990). Dialogue, dialectic, and conversation: A social perspective on the function of writing. Carbondale: Southern Illinois University Press.

Daniels, H. (Ed.). (2005). An introduction to Vygotsky ( $2^{\text {nd }}$ ed.). London: Routledge.

De Silva, N. H. (2007). A narrative-based collaborative writing tool for constructing coherent technical documents (Doctoral dissertation). [Abstract]. Retrieved from ProQuest Dissertations and Theses database. (AAT C829219)

Durst, R. K. (2006). Writing at the postsecondary level. In P. Smagorinsky (Ed.), Research on composition: Multiple perspectives on two decades of change (pp. 78-107). New York: Teachers College Press.

Ede, L., \& Lunsford, A. (1990). Singular texts/plural authors: Perspectives on collaborative writing. Carbondale \& Edwardsville: Southern Illinois University Press.

Facione, P. A. (2006). Significant contributions to collaborative scholarship \& tenure. Liberal Education, 92, 38-45.

Farmer, F. (Ed.). (1998). Landmark essays on Bakhtin, rhetoric, and writing. Mahwah, NJ: Hermagoras (Erlbaum).

Flower, L., \& Hayes, J. R. (1981). A cognitive process theory of writing. College Composition and Communication, 32(4), 365-387. 
Gere, A. R. (1987). Writing groups: History, theory, and implications. Carbondale: Southern Illinois University Press.

Gousseva-Goodwin, J. V. (2000). Collaborative writing assignments and on-line discussions in an advanced ESL composition class (Doctoral dissertation). [Abstract]. Retrieved from ProQuest Dissertations and Theses database. (AAT 9992078)

Halasek, K. (1999). A pedagogy of possibility: Bakhtinian perspectives on composition studies. Carbondale \& Edwardsville: Southern Illinois University Press.

Hamilton, M. L., \& Pinnegar, S. (1998). Conclusion: The value and promise of self-study. In M. L. Hamilton (Ed.), Reconceptualizing teaching practice: Self-study in teacher education (pp. 235-246). London: Falmer Press.

Harris, J. B., Freeman, T. L., \& Aerni, P. W. (2009). On becoming educational researchers: the importance of co generative mentoring. Mentoring $\mathcal{E}$ tutoring: Partnership in learning, 17(1), 23-39.

Hedegaard, M. (1996). The zone of proximal development as basis for instruction. In H. Daniels (Ed.), An introduction to Vygotsky (pp. 171-195). London: Routledge.

Hill, B. M. (2003). Collaborative literary creation and control: A socio-historic, technological and legal analysis. Retrieved from http://mako.cc/projects/collablit/ writing/BenjMakoHill-CollabLit_and_Control.pdf

Kim, H.-C. \& Eklundh, K. S. (2001). Reviewing practices in collaborative writing. Computer Supported Collaborative Work, 10, 247-259.

Klass-Soffian, R. (2004). Control vs. cooperation: A descriptive study of collaborative writing among bilingual Cuban American students in freshman composition. [Abstract]. Retrieved from ProQuest Dissertations \& Theses database. (AAT 3134078)

LeFevre, K. B. (1987). Invention as social act. Carbondale: Southern Illinois University Press.

Maher, D., Seaton, L., McMullen, C., Fitzgerald, T., Otsuji, E., \& Lee, A. (2008). "Becoming and being writers": The experiences of doctoral students in writing groups. Studies in Continuing Education, 30(3), 263-275. doi: $10.1080 / 01580370802439870$

Mitchell, J. M. (2003). Computer technology in teacher education: Tool for communication, medium for inquiry, object of critique (Doctoral dissertation). [Abstract]. Retrieved from Canada Theses Portal. (AMICUS No. 28231567)

Nixon, R. M. (2007). Collaborative and independent writing among adult Thai EFL learners (Doctoral dissertation). [Abstract]. Retrieved from Canada Theses Portal. (AMICUS No. 33765341)

Pithouse, K., Mitchell, C., \& Weber, S. (2009). Self-study in teaching and teacher development: A call to action. Educational Action Research, 17(1), 43-62.

Porras-Hernandez, L. H. (2001). Transference of efficacy beliefs and effects of selfefficacy performance spirals at group and individual levels (Doctoral dissertation). [Abstract]. Retrieved from Canada Theses Portal. (AMICUS No. 24739399) 
Ritchie, S. M., \& Rigano, D. L. (2007). Writing together metaphorically and bodily side-by-side: An inquiry into collaborative academic writing. Reflective Practice, 8(1), 123-135. doi: 10.1080/14623940601139087

Sakellariadis, A., Chromy, S., Martin, V., Speedy, J., Trahar, S., Williams, S., \& Wilson, S. (2008). Friend and foe? Technology in a collaborative writing group. Qualitative Inquiry, 14(7), 1205-1222. doi: 10.1177/ 1077800408324210

Standley, L. (2006) Cross-age peer-tutoring effects on the English literacy development and academic motivation of English language learners identified with, and referred for, mild and moderate disabilities (Doctoral dissertation). [Abstract]. Retrieved from ProQuest Dissertations and Theses database. (AAT 3224965)

Straw, S. B., Atkinson, L. E., Baardman, S. P., \& Sadowy, P. (1996). "That's the story of, that's the glory of ...": Multiple perspectives on co-authoring. English Quarterly, 28(2\&3), 51-59.

Sutherland, J., \& Topping, K. J. (1999). Collaborative creative writing in eightyear-olds: Comparing cross-ability fixed role and same-ability reciprocal role pairing. Journal of Research in Reading, 22(2), 154-179.

Sutton, M. W. (2002). Singular texts, plural authors, how many grades? Fair assessment of collaborative writing in first-year composition (Doctoral dissertation). [Abstract]. Retrieved from ProQuest Dissertations and Theses database. (AAT 3052077)

Topping, K. J., Nixon, J., Sutherland, J., \& Yarrow, F. (2000). Paired writing: A framework for effective collaboration. Reading (UKRA), 34(2), 79-89.

Vendramin, A. (2006). Investigating the impact of computer-based collaboration on elementary students' writing at Frost Road Elementary (British Columbia) (Master's thesis). [Abstract]. Retrieved from Canada Theses Portal. (AMICUS No. 33509454)

Vygotsky, L. S. (1962). Thought and language. (E. Hanfmann \& G. Vakar, Trans. \& Eds.) Cambridge, MA: The MIT Press.

Vygotsky, L. S. (1978). Mind in society: The development of higher psychological processes. (M. Cole, V. John-Steiner, S. Scribner, \& E. Souberman, Eds.) Cambridge, MA: Harvard University Press.

Wells, G. (1999). Dialogic inquiry: Toward a sociocultural practice and theory of education. Cambridge, UK: Cambridge University Press.

Wilson, (2008). Activity system analysis of a highly effective first-grade teacher and her students. (Doctoral dissertation). [Abstract]. Retrieved from Proquest Dissertations and Theses database. (AAT 3316368)

Wood, D., Bruner, J., \& Ross, G. (1976). The role of tutoring in problem solving. Journal of Child Psychology and Psychiatry, 17, 89-100. doi:10.1111/j.1469-7610.1976. tb00381.x

Yarrow, F. and Topping, K. J. (2001). Collaborative writing: The effects of metacognitive prompting and structured peer interaction. British Journal of Educational Psychology, 71(2), 261-282. 


\section{CONTACT INFORMATION}

Anita Ens

511 Sprague Street

Winnipeg, MB

R3G 2R9

anita.ens@mymts.net

Anita Ens is a doctoral candidate in Education at the University of Manitoba.

Karen Boyd is a doctoral candidate and instructor of preservice teachers in language and literacy at the University of Manitoba.

Allyson Matczuk works for Manitoba Education as the Early Literacy Intervention Consultant and the Reading Recovery Trainer for the Canadian Institute of Reading Recovery Western Region.

Warren Nickerson is a secondary English language arts teacher who currently works as a consultant for Manitoba Education.

\section{ACKNOWLEDGEMENTS}

The authors gratefully acknowledge the helpful comments and suggestions made by the anonymous reviewers of this article. Thanks also to Dr. Stan Straw for creating an assignment that necessitated our writing collaboratively.

This research was supported in part by the University of Manitoba Graduate Fellowship and the University of Manitoba Faculty of Education Graduate Student Research Support Scholarship. 